\title{
LOCAL HÖLDER ESTIMATES FOR GENERAL ELLIPTIC $p(x)$-LAPLACIAN EQUATIONS
}

\section{FENGPING YAO}

Abstract. In this paper we obtain the interior Hölder regularity of the gradients of weak solutions for general elliptic $p(x)$-Laplacian equations

$$
\operatorname{div}(a(x, \nabla u))=\operatorname{div}\left(|\mathbf{f}|^{p(x)-2} \mathbf{f}\right),
$$

under some proper assumptions on $a$ and the Hölder continuous functions $p, \mathbf{f}$.

Mathematics subject classification (2010): 35J60, 35J70.

Keywords and phrases: $C^{1, \alpha}$, Hölder, regularity, gradient, divergence, elliptic, $p(x)$-Laplacian.

\section{REFERENCES}

[1] E. ACERBi \& G. MingIOnE, Regularity results for a class of functionals with nonstandard growth, Arch. Ration. Mech. Anal., 156 (2001), 121-140.

[2] E. ACERBi \& G. Mingione, Regularity results for a stationary electro-rheologicaluids, Arch. Ration. Mech. Anal., 164 (3) (2002), 213-259.

[3] E. ACERBi \& G. Mingione, Gradient estimates for the $p(x)$-Laplacean system, J. Reine Angew. Math., 584 (2005), 117-148.

[4] S. BYUN \& L. WANG, Quasilinear elliptic equations with BMO coefficients in Lipschitz domains, Trans. Amer. Math. Soc., 359 (12) (2007), 5899-5913.

[5] S. BYUn, L. WANG \& S. ZHOU, Nonlinear elliptic equations with BMO coefficients in Reifenberg domains, J. Funct. Anal., 250 (1) (2007), 167-196.

[6] S. BYUN \& L. WANG, Nonlinear gradient estimates for elliptic equations of general type, Calc. Var. Partial Differ. Equ., 45 (3-4) (2012), 403-419.

[7] S. Challal \& A. Lyaghfouri, Gradient estimates for $p(x)$-harmonic functions, Manuscripta Math., 131 (3-4) (2010), 403-414.

[8] A. Coscia \& G. Mingione, Hölder continuity of the gradient of $p(x)$-harmonic mappings, C. R. Acad. Sci. Paris Math., 328 (4) (1999), 363-368.

[9] E. DiBenedetto \& J. Manfredi, On the higer integrability of the gradient of weak solutions of certain degenerate elliptic systems, Amer. J. Math., 115 (1993), 1107-1134.

[10] L. Diening, Riesz potential and Sobolev embeddings of generalized Lebesgue and Sobolev spaces $L^{p(.)}$ and $W^{k, p(.)}$, Math. Nach., 268 (1) (2004), 31-43.

[11] L. DIENING \& M. RÜŽIČKA, Calderón-Zygmund operators on generalized Lebesgue spaces $L^{p(\cdot)}$ and problems related to fluid dynamics, J. Reine Angew. Math., 563 (2003), 197-220.

[12] L. DIENING \& M. RÚŽIČKA, Integral operators on the halfspace in generalized Lebesgue spaces $L^{p(.)}$, part I, J. Math. Anal. Appl., 298 (2) (2004), 559-571.

[13] G. Di Fazio, D. Palagachev \& M. A. Ragusa, Global Morrey regularity of strong solutions to the Dirichlet problem for elliptic equations with discontinuous coefficients, J. Funct. Anal. 166 (2) (1999), 179-196.

[14] F. DuzaAR \& G. Mingione, Gradient estimates via non-linear potentials, Amer. J. Math., 133 (4) (2011), 1093-1149.

[15] X. FAN, J. Shen \& D. ZhaO, Sobolev embedding theorems for spaces $W^{k, p(x)}(\Omega)$, J. Math. Anal. Appl., 262 (2001), 749-760. 
[16] X. FAn \& D. ZhaO, On the spaces $L^{p(x)}(\Omega)$ and $W^{m, p(x)}(\Omega)$, J. Math. Anal. Appl., 263 (2001), 424-446.

[17] M. GIAQUinTA, Multiple integrals in the calculus of variations and nonlinear elliptic systems, Princeton University Press, 1983.

[18] P. HaRJulehto, Variable exponent Sobolev spaces with zero boundary values, Math. Bohem., 132 (2007), 125-136.

[19] J. KINNUNEN \& S. ZHOU, A local estimate for nonlinear equations with discontinuous coefficients, Comm. Partial Differential Equations, 24 (1999), 2043-2068.

[20] T. Kuusi \& G. Mingione, Universal potential estimates, J. Funct. Anal., 262 (10) (2012), 4205 4269.

[21] G. M. Lieberman, The natural generalization of the natural conditions of Ladyzenskaja and Ural'tzeva for elliptic equations, Comm. Partial Differential Equations, 16 (1991), 311-361.

[22] A. LYAGHFOURI, Hölder continuity of $p(x)$-superharmonic functions, Nonlinear Anal., 73 (8) (2010), 2433-2444.

[23] N. C. PHUC, Weighted estimates for nonhomogeneous quasilinear equations with discontinuous coefficients, Ann. Sc. Norm. Super. Pisa Cl. Sci. (5), 10 (1) (2011), 1-17.

[24] K. R. RAJAGOPAL \& M. RŮŽIČKA, Mathematical modeling of electro-rheological materials, Contin. Mech. Thermodyn., 13 (1) (2001), 59-78.

[25] M. RŮŽIČKA, Electrorheological Fluids: Modeling and Mathematical Theory, Lecture Notes in Math., vol. 1748, Springer, Berlin, 2000.

[26] L. WANG, Compactness methods for certain degenerate elliptic equations, J. Differential Equations, 107 (2) (1994), 341-350.

[27] C. ZHANG \& S. ZHOU, Hölder regularity for the gradients of solutions of the strong $p(x)$-Laplacian, J. Math. Anal. Appl., 389 (2) (2012), 1066-1077. 